\title{
Effectiveness of cytopenia prophylaxis for different filgrastim and pegfilgrastim schedules in a chemotherapy mouse model
}

\author{
Markus Scholz' \\ Manuela Ackermann² \\ Frank Emmrich ${ }^{2}$ \\ Markus Loeffler' \\ Manja Kamprad ${ }^{2}$ \\ 'Institute for Medical Informatics, \\ Statistics and Epidemiology, University \\ of Leipzig, Haertelstrasse 16-18, \\ 04I07 Leipzig, Germany; ${ }^{2}$ Institute for \\ Clinical Immunology and Transfusion \\ Medicine, University of Leipzig, \\ Johannisallee 30, 04I03 Leipzig, \\ Germany
}

\begin{abstract}
Objectives: Recombinant human granulocyte colony-stimulating factor (rhG-CSF) is widely used to treat neutropenia during cytotoxic chemotherapy. The optimal scheduling of rhG-CSF is unknown and can hardly be tested in clinical studies due to numerous therapy parameters affecting outcome (chemotherapeutic regimen, rhG-CSF schedules, individual covariables). Motivated by biomathematical model simulations, we aim to investigate different rhG-CSF schedules in a preclinical chemotherapy mouse model.
\end{abstract}

Methods: The time course of hematotoxicity was studied in CD-1 mice after cyclophosphamide (CP) administration. Filgrastim was applied concomitantly in a $2 \times 3$-factorial design of two dosing options $(2 \times 20 \mu \mathrm{g}$ and $4 \times 10 \mu \mathrm{g})$ and three timing options (directly, one, and two days after $\mathrm{CP}$ ). Alternatively, a single dose of $40 \mu \mathrm{g}$ pegfilgrastim was applied at the three timing options. The resulting cytopenia was compared among the schedules.

Results: Dosing and timing had a significant influence on the effectiveness of filgrastim schedules whereas for pegfilgrastim the timing effect was irrelevant. The best filgrastim and pegfilgrastim schedules exhibited equivalent toxicity. Monocytes dynamics performed analogously to granulocytes. All schedules showed roughly the same lymphotoxicity.

Conclusion: We conclude that effectiveness of filgrastim application depends heavily on its scheduling during chemotherapy. There is an optimum of timing. Dose splitting is better than concentrated applications. Effectiveness of pegfilgrastim is less dependent on timing.

Keywords: rhG-CSF, chemotherapy toxicity, mice, cyclophosphamide, cytopenia, neutropenia

\section{Introduction}

Conventional multi-drug, multi-cycle cytotoxic chemotherapy is still a major therapy option for many chemosensitive cancers and hematologic malignancies. Several studies have shown a clear relationship between dose density (defined as drug dose per time interval) and outcome (tumor control or survival). ${ }^{1-6}$ Accordingly, in some prospective clinical trials it has been shown that an overall increment in dose density could improve outcome (breast cancer, ${ }^{7,8}$ high-grade non-Hodgkin's lymphoma, ${ }^{9-11}$ Hodgkin's disease, ${ }^{12}$ transitional cell carcinoma, ${ }^{13}$ small-cell lung cancer ${ }^{14}$ ).

Because of a low tissue specificity of cytotoxic drugs, intensified chemotherapies increase the risk of side effects eg, with respect to the hematological system. Among these side effects common toxicity criteria (CTC) grade 3 and 4 neutropenia is especially problematic because of increased incidence of infections, hospitalization, antibiotic treatment, necessity to reduce therapy intensity and therapy-associated deaths. ${ }^{15-22}$ For prophylaxis or amelioration of neutropenia, recombinant human granulocyte colony-stimulating factor (rhG-CSF) is applied routinely. ${ }^{20,23-26}$

There are two major derivatives of rhG-CSF currently available: filgrastim and its pegylated counterpart, pegfilgrastim. filgrastim is rhG-CSF with a short half-life 
necessitating repeated applications per chemotherapy cycle. It is considered to be lineage specific and enhances granulopoiesis by mitotic activation of progenitors and precursors and by accelerated maturation. ${ }^{27-29}$ It is also assumed that $\mathrm{rhG}$-CSF reduces the rate of apoptosis in postmitotic maturing cells which induces an instantaneous increment in peripheral granulocyte counts in healthy subjects shortly after application. ${ }^{30,31}$

Filgrastim is degraded in vivo by unspecific renal elimination $^{32,33}$ and specifically, via G-CSF receptors or neutrophil elastase. ${ }^{34-39}$ In comparison, the rhG-CSF derivative pegfilgrastim has a prolonged half-life in vivo due to the reduction of renal clearance. ${ }^{40-42}$ Only one injection of pegfilgrastim is required during one cycle of chemotherapy. ${ }^{43}$ It is believed that pegfilgrastim has the same mechanisms of action as filgrastim. ${ }^{44}$ Clinical trials have shown that multiple injections of filgrastim and single injections of pegfilgrastim are roughly equivalent with respect to prophylaxis and treatment of neutropenia and infections. ${ }^{20,45-47}$ One meta-analysis showed a small advantage for pegfilgrastim regarding the rate of febrile neutropenia. ${ }^{48}$ On the other hand, the exact pharmacokinetic and dynamic properties of pegfilgrastim in comparison to filgrastim have not yet been analyzed well enough.

Because of the high potency of G-CSF with respect to the stimulation of granulopoiesis with different modes of action and the strong relationship between neutrophil counts and drug clearance, the application of G-CSF after bone marrow toxic chemotherapy results in a complex dynamic behavior of neutrophil cell counts which cannot easily be predicted. Furthermore, it is impossible to test all schedules of rhG-CSF application within the framework of clinical trials because of the large number of combinations of different dosing and timing options of both rhG-CSF and chemotherapeutic agents as well.

Based on a biomathematical model of human granulopoiesis, we predicted that the scheduling of multiple injections of filgrastim can be optimized regarding the degree of leukotoxicity. ${ }^{49,50}$ We suppose that there are optima of both dosing and timing of filgrastim as well which depend on the applied chemotherapeutic regimen. This model can be used for the planning of clinical trials. Recently we constructed a similar preliminary model for the murine situation in order to validate our modeling approach in an animal model. We predicted that timing of pegfilgrastim could be optimized as well in order to reduce granulotoxicity after cyclophosphamide (CP)-induced neutropenia. We also predicted that the timing effect is abrogated for highly dosed pegfilgrastim (publication in process).
Although there are several publications regarding the action of rhG-CSF in combination with chemotherapy, the lack of data does not permit to make more precise predictions of optimal schedules even in the murine situation: The application of cytotoxic drugs such as CP in mice has been studied extensively. ${ }^{51}$ Furthermore, there are several studies addressing the combined application of G-CSF and cytotoxic drugs or radiation. ${ }^{44,52-56}$ Bauhofer and colleagues $^{57}$ investigated the effect of G-CSF schedules in a septic rat model. Misaki and colleagues ${ }^{58}$ analysed different timings of G-CSF prior to CP application. Yankelevich and colleagues ${ }^{59}$ addressed the effect of timing of filgrastim on bone marrow cellularity but did not measured the time course in the nadir phase of circulating cells. Grigg and colleagues $^{60}$ optimized G-CSF scheduling with respect to stem cell harvest. However, to our knowledge there is no animal study which aims to determine the best scheduling of filgrastim and pegfilgrastim for prophylaxis of resulting blood cytopenia. Furthermore, published data does not fulfill our requirements for a systems-biologic modeling approach since multiple concomitant measurements of granulocytes, monocytes, lymphocytes, and G-CSF plasma concentrations are required in narrow time intervals after the application of cytotoxic drugs and under different G-CSF schedules ( compare $^{49,50}$ ).

Hence, in this report we explore the potential of different G-CSF schedules for filgrastim and pegfilgrastim in a chemotherapy mouse model. Our experiments have two major purposes: to assess and compare the hematotoxicity (especially neutropenia) of different application schedules in a factorial study design and to provide an improved data base for our ongoing systems - biologic modeling work.

\section{Methods}

\section{Experimental interventions}

Female, 8-week-old outbred Hsd:ICR mice (CD-1 ${ }^{\circledR}$, Harlan Sprague Dawley, Inc., obtained from a breeding stock from Charles River Breeding Laboratories) were used for this study. The mice were maintained in a defined flora animal facility.

The mice were injected either intraperitoneally with a chemotherapeutical agent at an injection volume of $200 \mu \mathrm{l}$ (cyclophosphamid $450 \mathrm{mg} / \mathrm{kg}$ (12 mg) [Endoxan, Baxter] or subcutaneously between the scapulae with rhG-CSF derivates at an injection volume of $100 \mu \mathrm{l}$ (filgrastim $10 \mu \mathrm{g}$ or $20 \mu \mathrm{g}$ [Neupogen, Amgen] or pegfilgrastim $40 \mu \mathrm{g}$ [Neulasta, Amgen]). All mass data regarding rhG-CSF applications are given as protein mass. 
After a combined treatment of these study drugs, peripheral blood of the mice was taken from the tail vein at specified time points. Blood was collected through heparinized capillaries (Rolf Greiner Biochemica) and transferred to heparinized tubes (Heparin-Natrium-25000, Ratiopharm). Rates of red blood cells, white blood cells, platelets and the relative and absolute contents of lymphocytes, monocytes, and granulocytes were determined by using an Animal Blood Counter (scil Vet abc, SCIL animal care company), which had been calibrated for mouse blood.

The levels of G-CSF present in plasma were assessed using the human G-CSF cytometric bead array kit (CBA, BD Biosciences, Pharmingen). Data were acquired on a FACS Calibur (Becton Dickinson) and analysed using the FCAP Array software (BD Biosciences, Pharmingen).

All measurements were supported by at least five mice.

\section{Study design}

A CP dose was chosen which results in a deep but reversible nadir of granulocyte cell counts in mice after a single application.

In order to analyse the effect of a concentrated versus a split application of G-CSF, we applied two doses of $20 \mu \mathrm{g}$ filgrastim $(2 \times 20 \mu \mathrm{g})$ in comparison to four doses of $10 \mu \mathrm{g}$ filgrastim $(4 \times 10 \mu \mathrm{g})$ on consecutive days after $\mathrm{CP}$ application. Applications were started directly ( $1 \mathrm{~h}$ later), one or two days after $\mathrm{CP}$ application in order to evaluate the effect of timing. Alternatively, we applied a fixed single dose of $40 \mu \mathrm{g}$ pegfilgrastim directly ( $1 \mathrm{~h}$ later), one or two days after $\mathrm{CP}$ application.

According to our design, we applied the same total protein mass of G-CSF in all experiments, which allows comparisons to be made regarding the effectiveness of different schedules.

\section{Evaluation of toxicity}

Hematotoxicity of an experimental setting was evaluated on the basis of the time course of the cell counts within the nadir phase for each single mouse separately. Three aggregated measures of toxicity were used in clinical practice; the minimal cell count (MCC), the duration of cytopenia (DoC), which is the total time below the normal cell count (NCC), and the area over the curve (AOC), defined as the area between NCC and the time course. For granulocytes it has been shown that MCC and DoC are both related to infections. ${ }^{61}$ The $\mathrm{MCC}$ can be estimated by assessing several time points in the nadir phase of cell counts. The DoC is most difficult to determine because the exact crossing points of time course and NCC can hardly be detected. The AOC is an integrated measure of MCC and DoC which can be estimated more easily by interpolation of the measurements in the nadir phase and integration of the resulting curves. No exact time points of crossing with the NCC are required to get a good estimate for AOC because it is mainly determined on the basis of the period with low cell counts.

\section{Statistical analysis}

Cell counts were logarithmized for all analyses to obtain normally distributed quantities. Therefore, we present geometric means and standard deviations (SD) for cell counts or G-CSF plasma concentrations throughout.

$\mathrm{NCC}$ is required for the calculation of $\mathrm{AOC}$ and has been determined for each cell line on the basis of all mice of all experiments. The MCC and AOC of single mice have been determined as described above. The effects of G-CSF derivative and its dosing and timing schedule on $\mathrm{MCC}$ and $\mathrm{AOC}$ have been calculated by ANOVA. For this purpose, MCC and $\mathrm{AOC}$ were adjusted for the corresponding initial values of cell counts (prior to intervention) since these values were often predictive for the nadir phase. In the case of global significance, contrasts were estimated for the corresponding quantities.

The occurrence of nadir was compared between the groups using the Jonckheere-Terpstra test for trends.

The calculation of the AOC was performed using the computational software package Matlab 7.0.4.365 (The MathWorks, Natick, MA, USA). Statistical analyses were performed using the statistical software package SAS 9.1 (SAS Institute Inc., Cary, NC, USA) and the statistical software package "R" (see http://www.r-project.org ${ }^{62}$ ).

\section{Results}

\section{Normal values}

On the basis of a total of 80 animals we determined normal values for granulocytes (mean $2.3 * 10^{6} \mathrm{ml}^{-1}$, SD 1.7), monocytes (mean $4.9 * 10^{5} \mathrm{ml}^{-1}$, SD 1.6), lymphocytes (mean $9.3 * 10^{6} \mathrm{ml}^{-1}$, SD 1.5), thrombocytes (mean $9.7 * 10^{8} \mathrm{ml}^{-1}$, SD 1.3), and red blood cells (mean $8.2 * 10^{9} \mathrm{ml}^{-1}$, SD 1.2). These values were used to assess the hematotoxicity of different G-CSF schedules in the next steps.

\section{Time courses after application of $12 \mathrm{mg} \mathrm{CP}$ alone Granulocytes}

Application of a single dose of $12 \mathrm{mg} \mathrm{CP}$ resulted in a deep but reversible decline of granulocytes (see Figure 1A). 

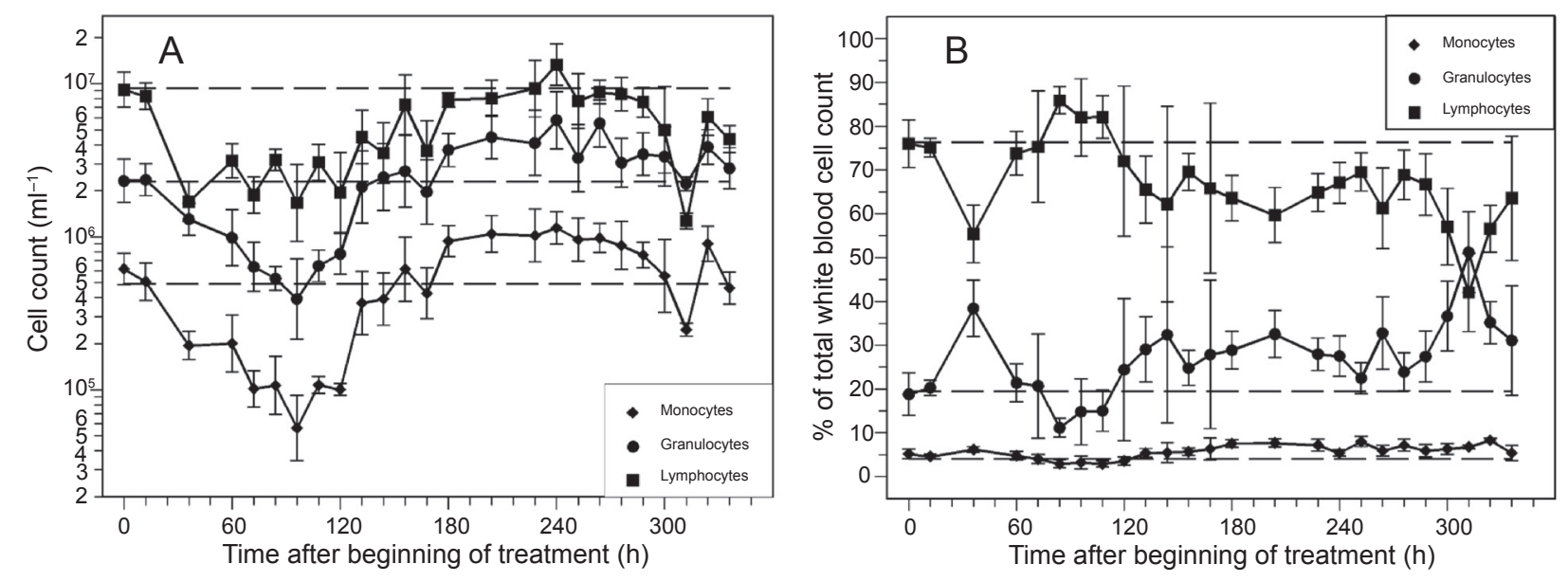

Figure I Cell counts (A) and rates (B) of granulocytes, monocytes and lymphocytes after application of a single dose of I2 mg CP. Each point represents the geometric mean of 5-16 mice. Bars correspond to the geometric standard deviation. Dashed line represents the corresponding population geometric mean in untreated mice.

The lowest granulocyte counts were measured between $72 \mathrm{~h}$ and $108 \mathrm{~h}$ after CP. Granulocytes have been recovered at $132 \mathrm{~h}$ followed by a time period of approximately five days with overcompensation. The rate of granulocytes with respect to the total cell count of white blood cells was lower than normal in the nadir phase of granulocytes. It was higher than normal shortly after $\mathrm{CP}$ and during the period of recovery (see Figure 1B).

\section{Monocytes}

Monocyte nadir occurred between $84 \mathrm{~h}$ and $120 \mathrm{~h}$ after CP. Recovery was reached at $156 \mathrm{~h}$ followed by a five-day period of overcompensation (see Figure 1A). Hence, monocyte dynamics are similar to granulocyte dynamics. The same holds for the rate of monocytes (see Figure 1B).

\section{Lymphocytes}

Lymphocyte counts also expressed a deep nadir with a plateau of low counts lasting between $36 \mathrm{~h}$ and $120 \mathrm{~h}$ after CP (see Figure 1A). Recovery was reached approximately $180 \mathrm{~h}$ after CP. We observed a second deep nadir of lymphocytes at $312 \mathrm{~h}$. The rate of lymphocytes was higher than normal in the nadir phase of granulocytes. At all other time points, the rate was lower than normal (see Figure 1B).

\section{Other lineages}

The time course of thrombocytes showed no thrombopenic phase (data not shown), indicating that the $\mathrm{CP}$ application is not suitable to study chemotherapy-induced thrombopenia in the mouse. Red blood cells showed only a mild decrease after $\mathrm{CP}$, and therefore, they were not analyzed for toxicity (data not shown). Hence, we restricted our attention to granulocytes, monocytes, and lymphocytes in the following.

\section{Time courses after combined application of $12 \mathrm{mg} \mathrm{CP}$ and filgrastim in different schedules}

\section{Granulocytes}

The time courses of granulocytes and corresponding G-CSF plasma concentrations for the timing options of filgrastim are shown in Figures 2 and 3, separately for the two dosing options (two times $20 \mu \mathrm{g}$ versus four times $10 \mu \mathrm{g}$ ). Due to the short half-life of filgrastim in vivo, G-CSF plasma concentrations drop quickly after stopping G-CSF applications.

$\mathrm{CP}$ in combination with the different filgrastim schedules also resulted in a clear granulopenic phase where the lowest granulocyte counts were measured between $60 \mathrm{~h}$ and $108 \mathrm{~h}$ (see Table 1). We recognized that nadirs in the day 0 schedules appear significantly earlier than in the other schedules $(\mathrm{p}<0.0001)$.

MCC and AOC were calculated for all mice individually and were adjusted for the initial counts. Statistics of these quantities can be read in Table 2 for all schedules and in comparison to the results obtained without G-CSF support.

With respect to MCC the best filgrastim schedule was day $1,4 \times 10 \mu \mathrm{g}$ which was significantly better than all other schedules. The worst one was day $0,2 \times 20 \mu \mathrm{g}$ which was even worse than no G-CSF at all. Global testing of differences between the schedules was significant $(p=0.0047)$. Independent of timing, the scheduling for $4 \times 10 \mu \mathrm{g}$ was significantly better than $2 \times 20 \mu \mathrm{g}(\mathrm{p}=0.048)$. Independent of dosing, the timing on day 0 was significantly worse than the timing on day $1(p=0.0014)$. Other differences with respect to timing were not significant.

With respect to $\mathrm{AOC}$ the best filgrastim schedule again was day $1,4 \times 10 \mu \mathrm{g}$. The worst one was day $0,2 \times 20 \mu \mathrm{g}$ 

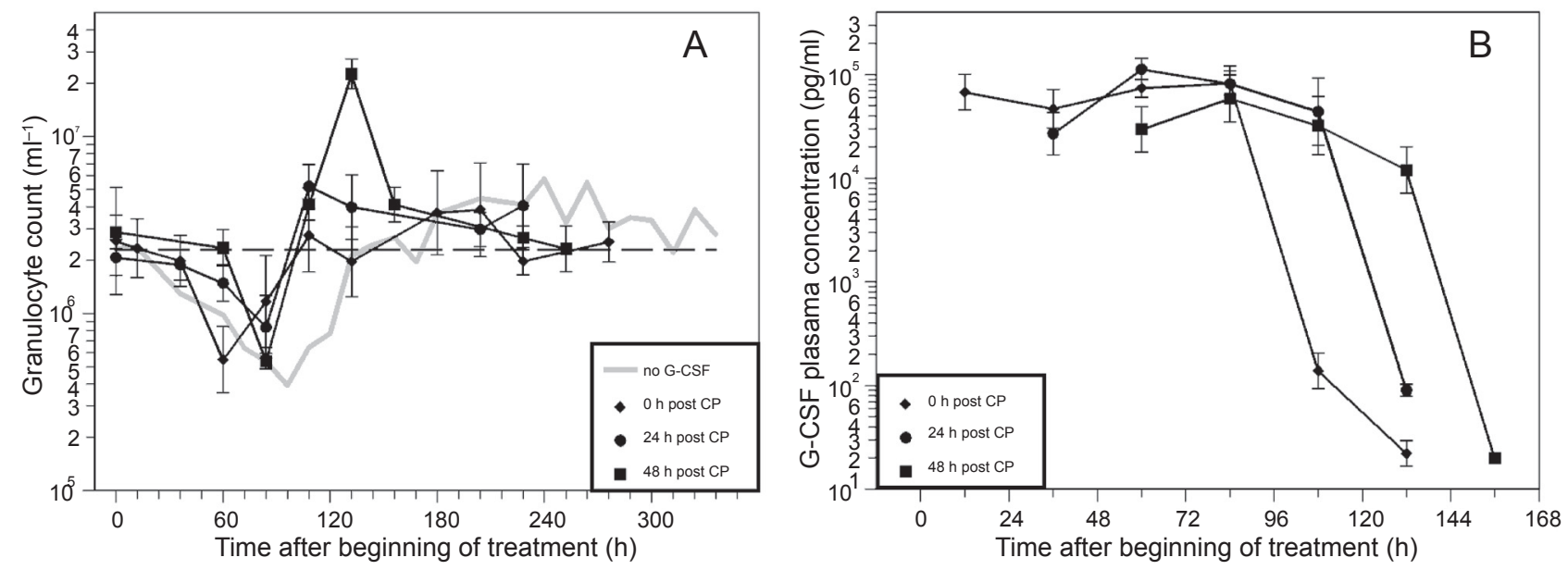

Figure 2 A) Granulocyte count in mice after application of a single dose of $12 \mathrm{mg} \mathrm{CP}$ and four doses of filgrastim $(10 \mu \mathrm{g})$ on four consecutive days after $\mathrm{CP}$ treatment; starting directly, one or two days after CP. Each point represents the geometric mean of 5-10 mice. Bars correspond to the geometric standard deviation. Dashed line represents the population geometric mean in untreated mice. For comparison, grey line of no G-CSF application is plotted as in Figure 2. B) Corresponding G-CSF plasma concentrations.

with toxicity comparable to no G-CSF application at all. For the $2 \times 20 \mu \mathrm{g}$ dosing schedule it was best to apply filgrastim later, on day 2. Global testing of differences between schedules was significant $(\mathrm{p}<0.0001)$. Independent of timing, the schedules $4 \times 10 \mu \mathrm{g}$ were significantly better than $2 \times 20 \mu \mathrm{g}(\mathrm{p}<0.0001)$. Independent of dosing, the timing day 0 was significantly worse than the timing day $2(\mathrm{p}=0.020)$.

\section{Monocytes}

$\mathrm{CP}$ in combination with the filgrastim schedules resulted in a clear monocytopenic phase. The lowest counts were measured between $60 \mathrm{~h}$ and $132 \mathrm{~h}$ (see Table 1). In the day 0 schedules the nadir occurred earlier than in the day 1 or day 2 schedules $(p=0.0004)$.

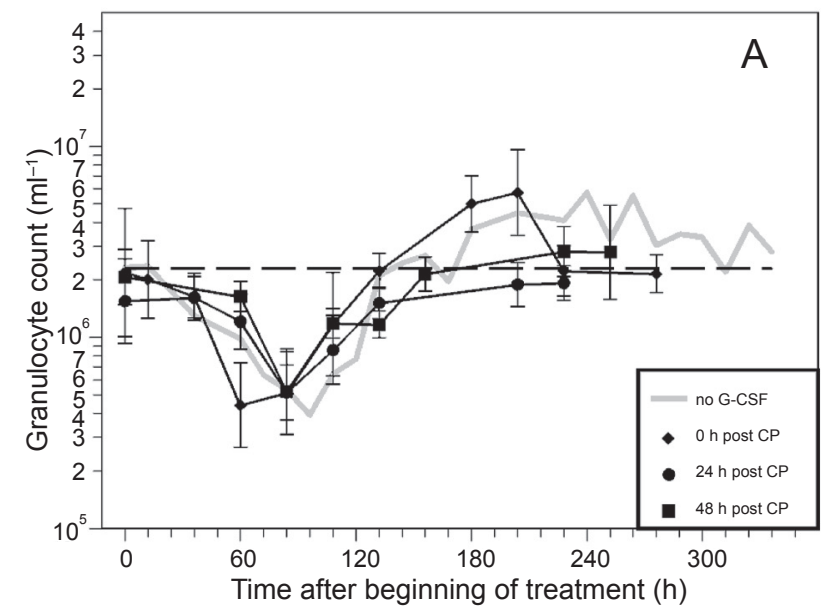

MCC and AOC statistics for monocytes can be found in Table 2 . With respect to MCC the best filgrastim schedule was day $1,4 \times 10 \mu \mathrm{g}$. The worst schedule was day $0,2 \times 20 \mu \mathrm{g}$. Global testing was significant ( $p=0.0005)$. Independent of timing, the schedules $4 \times 10 \mu \mathrm{g}$ were significantly better than $2 \times 20 \mu \mathrm{g}(\mathrm{p}=0.049)$. Independent of dosing, the timing day 0 was significantly worse than the timing day $1(\mathrm{p}=0.0017)$.

For AOC the best scheduling again was day $1,4 \times 10 \mu \mathrm{g}$, the worst was day $2,2 \times 20 \mu \mathrm{g}$. Global test of differences was significant $(p=0.010)$. However, there are no significant general dosing and timing effects.

\section{Lymphocytes}

$\mathrm{CP}$ in combination with the different G-CSF schedules also resulted in a clear lymphopenic phase where the lowest count

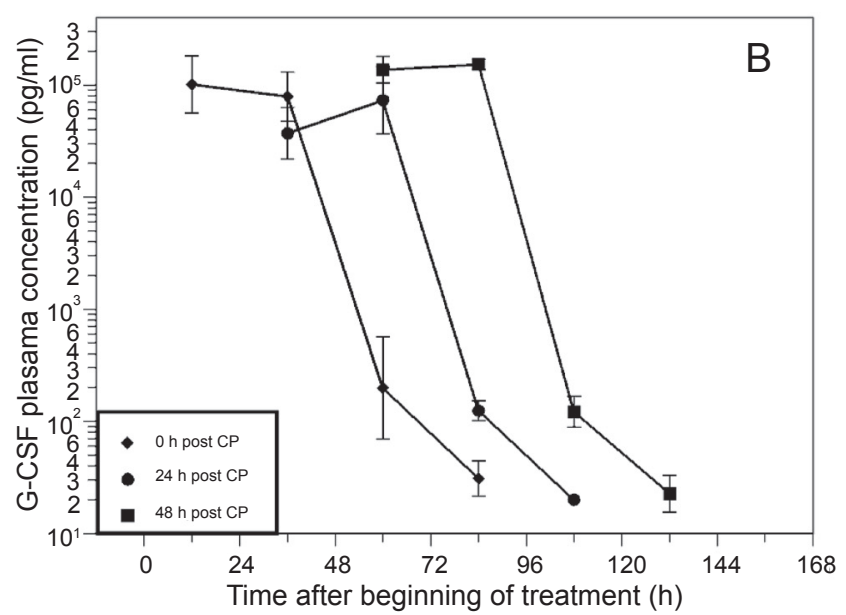

Figure 3 A) Granulocyte count in mice after application of a single dose of I 2 mg CP and two doses of filgrastim ( $20 \mu \mathrm{g})$ on two consecutive days after CP treatment; starting directly, one day or two days after CP. Each point represents the geometric mean of 5-10 mice. Bars correspond to the geometric standard deviation. Dashed line represents the population geometric mean in untreated mice. For comparison, grey line of no G-CSF application is plotted as in Figure 2. B) Corresponding G-CSF plasma concentrations. 
Table I Nadir times of granulocytes, monocytes, and lymphocytes: Number of animals reaching the nadir at specified time points are presented for all cell lines and G-CSF schedules

\begin{tabular}{|c|c|c|c|c|c|c|c|c|c|c|}
\hline & \multirow{3}{*}{$\begin{array}{l}\text { G-CSF } \\
\text { Schedule } \\
\text { Nadir times }\end{array}$} & \multirow{2}{*}{\multicolumn{3}{|c|}{$\frac{\text { Pegfilgrastim }}{\mathrm{I} \times \mathbf{4 0 \mu \mathrm { g }}}$}} & \multicolumn{6}{|c|}{ Filgrastim } \\
\hline & & & & & \multicolumn{3}{|l|}{$4 \times 10 \mu \mathrm{g}$} & \multicolumn{3}{|l|}{$2 \times 20 \mu g$} \\
\hline & & $\begin{array}{l}\text { Day } 0 \\
(N=8)\end{array}$ & $\begin{array}{l}\text { Day I } \\
(N=8)\end{array}$ & $\begin{array}{l}\text { Day } 2 \\
(N=8)\end{array}$ & $\begin{array}{l}\text { Day } 0 \\
(N=10)\end{array}$ & $\begin{array}{l}\text { Day I } \\
(N=5)\end{array}$ & $\begin{array}{l}\text { Day } 2 \\
(N=5)\end{array}$ & $\begin{array}{l}\text { Day } 0 \\
(N=\mid 0)\end{array}$ & $\begin{array}{l}\text { Day I } \\
(N=5)\end{array}$ & $\begin{array}{l}\text { Day } 2 \\
(N=5)\end{array}$ \\
\hline \multirow[t]{3}{*}{ Granulocytes } & $60 \mathrm{~h}$ & 5 & 0 & 2 & 7 & 0 & 0 & 4 & 0 & 0 \\
\hline & $84 \mathrm{~h}$ & 3 & 8 & 6 & 3 & 5 & 5 & 6 & 4 & 5 \\
\hline & $108 \mathrm{~h}$ & 0 & 0 & 0 & 0 & 0 & 0 & 0 & 1 & 0 \\
\hline \multirow[t]{4}{*}{ Monocytes } & $60 \mathrm{~h}$ & 4 & 0 & 1 & 4 & 0 & 0 & 4 & 0 & 0 \\
\hline & $84 \mathrm{~h}$ & 4 & 8 & 3 & 5 & 4 & 5 & 6 & 3 & 2 \\
\hline & $108 \mathrm{~h}$ & 0 & 0 & 4 & 1 & 0 & 0 & 0 & 2 & 2 \\
\hline & $132 \mathrm{~h}$ & 0 & 0 & 0 & 0 & I & 0 & 0 & 0 & 1 \\
\hline \multirow[t]{4}{*}{ Lymphocytes } & $36 \mathrm{~h}$ & 0 & 0 & 0 & 0 & 0 & 0 & 2 & 0 & 0 \\
\hline & $60 \mathrm{~h}$ & 6 & 1 & 3 & 9 & 3 & 1 & 6 & 1 & 1 \\
\hline & $84 \mathrm{~h}$ & 2 & 6 & 3 & 0 & 1 & 4 & 1 & 2 & 3 \\
\hline & $108 \mathrm{~h}$ & 0 & I & 2 & 1 & 1 & 0 & I & 2 & 1 \\
\hline
\end{tabular}

was reached between $36 \mathrm{~h}$ and $108 \mathrm{~h}$ (see Table 1). Again, the occurrence of nadir is earlier in the day 0 schedules in comparison to the day 1 and 2 schedules ( $p=0.0007)$.

MCC and AOC statistics of lymphocytes can be read from Table 2. Once more, with respect to MCC the best filgrastim schedule was day $1,4 \times 10 \mu \mathrm{g}$. The worst schedule was day $0,4 \times 10 \mu \mathrm{g}$. However, global test of differences between schedules was not significant $(p=0.059)$. Hence, contrasts were not calculated. For AOC the best schedule was day $1,4 \times$ $10 \mu \mathrm{g}$, the worst was day $0,4 \times 10 \mu \mathrm{g}$. Again, global test was not significant $(\mathrm{p}=0.28)$. Contrasts were not calculated.

These results indicate that the different filgrastim schedules had no significant impact on lymphocyte dynamics.

\section{Time course after combined application of $12 \mathrm{mg} \mathrm{CP}$ and pegfilgrastim in different schedules \\ Granulocytes}

The time courses of granulocytes and corresponding G-CSF plasma concentrations of the different pegfilgrastim timing schedules are shown in Figure 4. Due to improved pharmacokinetic properties of pegfilgrastim, plasma concentrations dropped much later than for filgrastim applications. The nadir of granulocytes appeared between $60 \mathrm{~h}$ and $84 \mathrm{~h}$ (Table 1). Again, a shift towards an earlier occurrence of nadir could be observed in the day 0 group $(\mathrm{p}=0.0064)$.

With respect to MCC the best pegfilgrastim timing was day 1 (Table 2). But there were no significant differences between the pegfilgrastim schedules and the control group with no G-CSF support $(\mathrm{p}=0.081)$.

With respect to $\mathrm{AOC}$ the best pegfilgrastim timing was day 1. Global testing of differences between the schedules was significant ( $p<0.0001)$. Pegfilgrastim schedules were always better than no G-CSF ( $p<0.0001$ for all timing options). On the other hand there were no significant differences between the three timing options. Hence, the timing options can be considered to be equivalent with respect to both MCC and AOC.

\section{Monocytes}

The nadir was reached between $60 \mathrm{~h}$ and $108 \mathrm{~h}$ (Table 1). In the day 0 schedule, the nadir occurred earlier than in the other schedules $(\mathrm{p}=0.0053)$.

Pegfilgrastim timing on day 1 was best with respect to MCC (Table 2). All three pegfilgrastim schedules were significantly better than the control group without G-CSF support (day $0: p=0.013$, day $1: p=0.0024$, day $2: p=0.013$ ), but there were no significant differences between the pegfilgrastim timings.

Global testing was also significant for AOC $(p<0.0001)$. Pegfilgrastim timing at day 1 was the best. All pegfilgrastim schedules were better than no G-CSF (all p $<0.0001$ ). On the other hand there were no significant differences between the three timing options.

Consequently, the three timing options can be considered to be equivalent with respect to both MCC and AOC. 
Table 2 Characteristics for the granulotoxicity, monocytotoxicity, and lymphotoxicity for all schedules considered.We present arithmetic mean and standard deviation (in parentheses) for logarithmized MCC and AOC adjusted for initial cell counts. Both low MCC and high $A O C$ indicate high toxicity as well. Grey areas indicate the schedules with corresponding lowest toxicity for both filgrastim and pegfilgrastim as well

\begin{tabular}{|c|c|c|c|c|c|c|c|c|c|c|c|}
\hline & \multirow{3}{*}{$\begin{array}{l}\text { G-CSF } \\
\text { schedule }\end{array}$} & \multirow[t]{3}{*}{ Without } & \multirow{2}{*}{\multicolumn{3}{|c|}{$\frac{\text { Pegfilgrastim }}{\mathrm{I} \times 40 \mu \mathrm{g}}$}} & \multicolumn{6}{|c|}{ Filgrastim } \\
\hline & & & & & & \multicolumn{3}{|c|}{$4 \times 10 \mu g$} & \multicolumn{3}{|c|}{$2 \times 20 \mu \mathrm{g}$} \\
\hline & & & Day 0 & Day I & Day 2 & Day 0 & Day I & Day 2 & Day 0 & Day I & Day 2 \\
\hline \multirow[t]{2}{*}{ Granulocytes } & $\begin{array}{l}\mathrm{MCC} \\
\left(\log \mathrm{ml}^{-1}\right)\end{array}$ & $\begin{array}{l}13.0 \\
(0.35)\end{array}$ & $\begin{array}{l}13.4 \\
(0.59)\end{array}$ & $\begin{array}{l}13.5 \\
(0.30)\end{array}$ & $\begin{array}{l}13.5 \\
(0.52)\end{array}$ & $\begin{array}{l}13.1 \\
(0.22)\end{array}$ & $\begin{array}{l}13.7 \\
(0.44)\end{array}$ & $\begin{array}{l}13.1 \\
(0.08)\end{array}$ & $\begin{array}{l}12.8 \\
(0.33)\end{array}$ & $\begin{array}{l}13.2 \\
(0.21)\end{array}$ & $\begin{array}{l}13.2 \\
(0.52)\end{array}$ \\
\hline & $\begin{array}{l}A O C \\
\text { (h) }\end{array}$ & $\begin{array}{l}131.0 \\
(36.7)\end{array}$ & $\begin{array}{l}48.0 \\
(28.4)\end{array}$ & $\begin{array}{l}46.4 \\
(19.9)\end{array}$ & $\begin{array}{l}46.8 \\
(19.7)\end{array}$ & $\begin{array}{l}79.5 \\
(26.6)\end{array}$ & $\begin{array}{l}39.6 \\
(15.4)\end{array}$ & $\begin{array}{l}44.6 \\
(2.7)\end{array}$ & $\begin{array}{l}111.6 \\
(36.0)\end{array}$ & $\begin{array}{l}108.7 \\
(22.8)\end{array}$ & $\begin{array}{l}90.2 \\
(17.1)\end{array}$ \\
\hline \multirow[t]{2}{*}{ Monocytes } & $\begin{array}{l}\mathrm{MCC} \\
\left(\log \mathrm{ml}^{-1}\right)\end{array}$ & $\begin{array}{l}11.1 \\
(0.42)\end{array}$ & $\begin{array}{l}11.6 \\
(0.37)\end{array}$ & $\begin{array}{l}11.7 \\
(0.30)\end{array}$ & $\begin{array}{l}11.6 \\
(0.20)\end{array}$ & $\begin{array}{l}11.5 \\
(0.22)\end{array}$ & $\begin{array}{l}11.9 \\
(0.26)\end{array}$ & $\begin{array}{l}11.4 \\
(0.11)\end{array}$ & $\begin{array}{l}\text { II.I } \\
(0.37)\end{array}$ & $\begin{array}{l}11.5 \\
(0.23)\end{array}$ & $\begin{array}{l}11.6 \\
(0.30)\end{array}$ \\
\hline & $\begin{array}{l}A O C \\
\text { (h) }\end{array}$ & $\begin{array}{l}158.8 \\
(36.1)\end{array}$ & $\begin{array}{l}90.5 \\
(42.1)\end{array}$ & $\begin{array}{l}81.1 \\
(19.3)\end{array}$ & $\begin{array}{l}83.7 \\
(20.0)\end{array}$ & $\begin{array}{l}135.5 \\
(2 \mid .5)\end{array}$ & $\begin{array}{l}98.4 \\
(15.5)\end{array}$ & $\begin{array}{l}99.9 \\
(13.7)\end{array}$ & $\begin{array}{l}129.4 \\
(35.6)\end{array}$ & $\begin{array}{l}125.0 \\
(31.3)\end{array}$ & $\begin{array}{l}142.3 \\
(26.4)\end{array}$ \\
\hline \multirow[t]{2}{*}{ Lymphocytes } & $\begin{array}{l}\text { MCC } \\
\left(\log \mathrm{ml}^{-1}\right)\end{array}$ & $\begin{array}{l}14.6 \\
(0.43)\end{array}$ & $\begin{array}{l}\mid 4.5 \\
(0.40)\end{array}$ & $\begin{array}{l}14.4 \\
(0.32)\end{array}$ & $\begin{array}{l}14.6 \\
(0.19)\end{array}$ & $\begin{array}{l}14.0 \\
(0.44)\end{array}$ & $\begin{array}{l}14.8 \\
(0.15)\end{array}$ & $\begin{array}{l}14.7 \\
(0.21)\end{array}$ & $\begin{array}{l}14.3 \\
(0.34)\end{array}$ & $\begin{array}{l}14.5 \\
(0.25)\end{array}$ & $\begin{array}{l}14.2 \\
(1.1)\end{array}$ \\
\hline & $\begin{array}{l}A O C \\
\text { (h) }\end{array}$ & $\begin{array}{l}172.9 \\
(59.2)\end{array}$ & $\begin{array}{l}162.9 \\
(71.3)\end{array}$ & $\begin{array}{l}164.8 \\
(20.4)\end{array}$ & $\begin{array}{l}146.8 \\
(34.0)\end{array}$ & $\begin{array}{l}217.0 \\
(53.3)\end{array}$ & $\begin{array}{l}169.6 \\
(28.6)\end{array}$ & $\begin{array}{l}182.6 \\
(30.3)\end{array}$ & $\begin{array}{l}202.2 \\
(24.8)\end{array}$ & $\begin{array}{l}205.2 \\
(25.9)\end{array}$ & $\begin{array}{l}203.5 \\
(39.3)\end{array}$ \\
\hline
\end{tabular}

\section{Lymphocytes}

For lymphocytes the nadir was reached between $60 \mathrm{~h}$ and $108 \mathrm{~h}$ (Table 1). A shift towards earlier nadirs for the day 0 schedule could be detected $(\mathrm{p}=0.0094)$.

With respect to MCC and AOC the lymphotoxicity was not significantly different between the schedules, ie, between the control group and the three timing options of pegfilgrastim $(\mathrm{MCC} p=0.76$, AOC $\mathrm{p}=0.85)$.

\section{Comparison of pegfilgrastim and filgrastim}

For granulocytes, we compared the best schedule for filgrastim (day $1,4 \times 10 \mu \mathrm{g}$ ) with the best schedule for pegfilgrastim (day 1) and found no significant differences with respect to MCC $(p=0.39)$ and AOC $(p=0.33)$. The same holds true for monocytes MCC $(p=0.26)$ and AOC $(p=0.27)$.

\section{Discussion}

In the present study we aimed to explore the potential of different filgrastim and pegfilgrastim application schedules of constant total doses after $\mathrm{CP}$-induced hematotoxicity. Major conclusions are that the scheduling of filgrastim is crucial for the recovery of granulocytes. There is an optimal timing. Splitting of the dose over several injections is better than more concentrated application. Pegfilgrastim application is
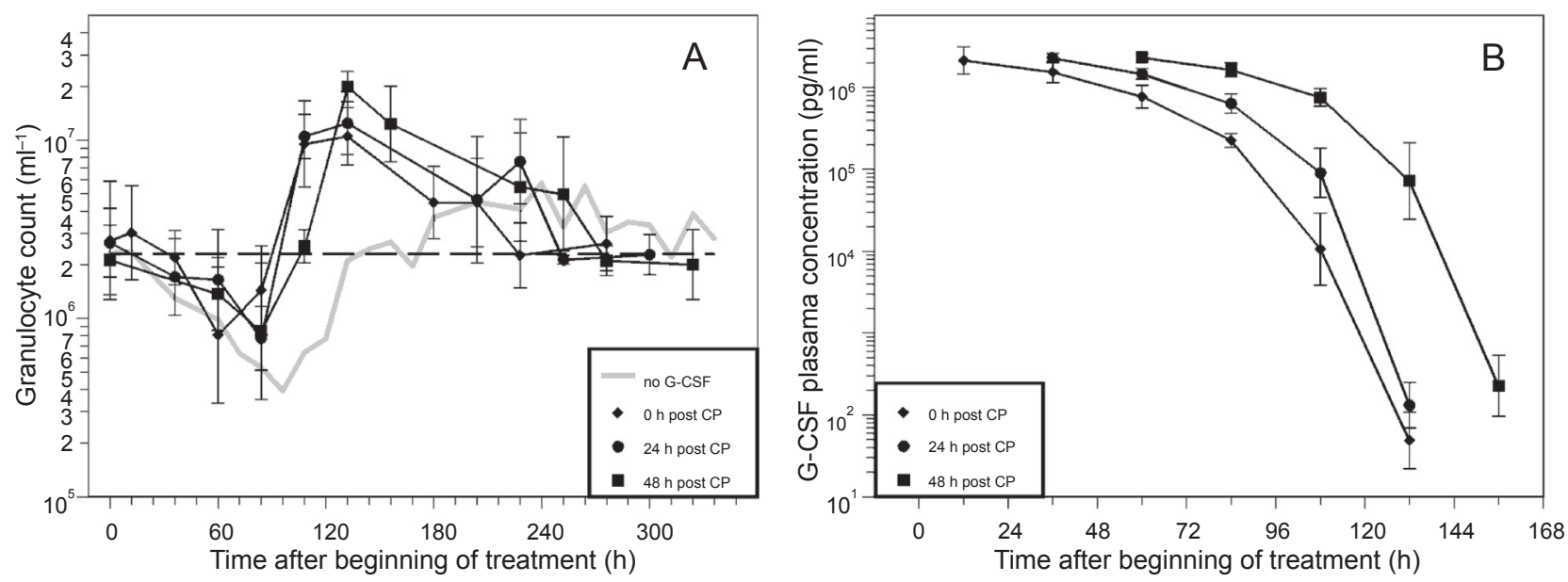

Figure 4 A) Granulocyte count in mice after application of a single dose of $12 \mathrm{mg} \mathrm{CP}$ and one dose of pegfilgrastim (40 $\mu \mathrm{g})$ directly, one or two days after CP. Each point represents the geometric mean of eight mice. Bars correspond to the geometric standard deviation. Dashed line represents the population geometric mean in untreated mice. For comparison, grey line of no G-CSF application is plotted as in Figure 2. B) Corresponding G-CSF plasma concentrations. 
more robust. No effects of different timing were found for the relatively high dose used. The best filgrastim schedule is equivalent to pegfilgrastim. Monocytes react concomitant to granulocytes. Lymphotoxicity was not affected by the G-CSF schedules. Starting G-CSF treatment directly after CP results in earlier occurrence of the nadir of all cell counts. However, toxicity was not necessarily higher. Daily concomitant measurements of both, granulocytes, monocytes, lymphocytes, and G-CSF plasma concentrations as well are available now and can be used to improve our biomathematical models.

For the experiments, we used outbred CD1 mice in order to allow similar variances of toxic reactions as in the human situation.

We applied $12 \mathrm{mg}$ of $\mathrm{CP}$ which resulted in a deep but reversible nadir of granulocytes, monocytes and lymphocytes. Red blood cell counts could not be analyzed with respect to hematotoxicity, since the long half-life of erythrocytes prevents anemia in this moderately cytotoxic chemotherapy setting as far as possible. Platelets also showed no significant reduction in cell counts in accordance with earlier observations. ${ }^{63,64}$

Concomitantly to the $\mathrm{CP}$ administration, we applied G-CSF in different dosing and timing schedules. Filgrastim was administered in a $2 \times 3$-factorial design with two dosing variants $(2 \times 20 \mu \mathrm{g}$ daily and $4 \times 10 \mu \mathrm{g}$ daily $)$ and with three timing variants (directly, 1 day, 2 days after CP). Pegfilgrastim was administered with a fixed dose of $40 \mu \mathrm{g}$ directly, 1 day or 2 days after CP. Numerous evidence has been collected about a clear dose response relationship for both filgrastim and pegfilgrastim (filgrastim: for example, ${ }^{34,65}$ pegfilgras$\left.\operatorname{tim}^{55,66}\right)$. Hence, there is no question that a higher total dose will result in lower toxicity when applied properly. Therefore, in our study we kept the parameter of total dose constant in order to analyze the remaining effects of different schedules. We used a relatively high dose of filgrastim and pegfilgrastim in order to obtain informative time courses of cytokine concentrations for later pharmacokinetic modeling.

In order to compare cytopenia between the G-CSF schedules we used two surrogate markers. It has been shown that MCC of granulocytes is related to adverse events in cancer therapy of humans. ${ }^{61}$ Furthermore, in clinical studies it is used to define grades of hematotoxicity. However, we showed that variance of MCC was small between schedules. Therefore, we also considered AOC which is a combined measure of $\mathrm{MCC}$ and DoC. In general AOC had more power than MCC to differentiate between schedules. On the other hand, in our data AOC is strongly (inversely) correlated to MCC (granulocytes: $r=-0.78$, monocytes $r=-0.75$, lymphocytes $r=-0.86$, Pearson's correlation coefficient). Both markers of toxicity are based on the pure number of cells and not on their function, which is a limitation of our study. ${ }^{67}$

First, we analyzed the granulocyte dynamics of the schedules. For filgrastim, the schedule on day $1,4 \times 10 \mu \mathrm{g}$ was best with respect to both MCC and AOC. The worst schedule was day $0,2 \times 20 \mu \mathrm{g}$ which exhibited toxicity comparable to no G-CSF at all. Dose splitting $4 \times 10 \mu \mathrm{g}$ was always significantly better than $2 \times 20 \mu \mathrm{g}$, independent of timing. Furthermore, the timing at day 0 was always significantly worse than later timing, independent of dosing. It is interesting to explain these observations in more detail. The effect of dose splitting could be favorable because of the observation that dose response curves for filgrastim are saturated at a certain level. ${ }^{34}$ In accordance, Tanaka and colleagues ${ }^{68}$ showed that subcutaneous injection with a lower initial concentration but higher sustained concentration is more effective than intravenous injection. The effect of timing can be understood by two competitive processes. At first, stimulation of bone marrow, including increased proliferation and maturation should start early. On the other hand, bone marrow reserve is activated directly after G-CSF application causing an immediate increment of cell counts. ${ }^{30,31,69}$ This should best happen directly in the nadir phase of cell counts. Hence, we suppose that there is an optimum between early and late timing which cannot easily be predicted. This has also been found qualitatively by model simulations of our biomathematical model of human granulopoiesis. ${ }^{50,70}$ For the dosing $4 \times 10 \mu \mathrm{g}$ the optimum was day 1 . Interestingly, for the dosing $2 \times 20 \mu \mathrm{g}$ it might be better to start at day 2 . In our experiments the timing day 0 was too early, resulting in an earlier nadir and worse recovery. Clinicians also do not recommend starting G-CSF directly after chemotherapy because of possible interactions with chemotherapy. ${ }^{71}$ However, so far there was no evidence for increased toxicity after early administration of filgrastim. ${ }^{72}$

For pegfilgrastim, the best scheduling was day 1 . However, there were no significant differences between the three timing options for both MCC and AOC. Although with insignificantly lower MCC and higher AOC, the timing day 0 was the worst. Nadir occurred significantly earlier than in the day 1 and 2 timing schedules. Again, in clinical practice it is not recommended to apply pegfilgrastim directly after chemotherapy, however there is a lack of clinical evidence regarding worse side effects..$^{71,73,74}$ We found that for pegfilgrastim the effect of timing is not as critical as it is for filgrastim. One reason could be that bone marrow 
stimulation with respect to maturation or release of bone marrow reserve is a bit lower for pegfilgrastim than for filgrastim. This could be explained by an interaction of G-CSF receptors and pegylation. ${ }^{75} \mathrm{We}$ also plan further experiments with respect to this issue. On the other hand, from model simulations we expect that timing of pegfilgrastim might play a role for low dose applications which were not tested in our experiments.

We compared the best filgrastim and pegfilgrastim schedules and found no differences with respect to MCC and ANC. This implies that filgrastim is equivalent to pegfilgrastim when used properly in accordance with other clinical observations by many authors. ${ }^{20,45-47}$ Since we applied the same protein mass in all of the schedules, we conclude that the superior pharmacokinetic properties of pegfilgrastim (longer half-life) are diminished to some extent by the inferior potency of bone marrow stimulation.

The effect of G-CSF on monocyte dynamics has not been as well investigated as it has for granulocytes. Some studies observed a beneficial effect of G-CSF on monocytosis under infection or chemotherapy. ${ }^{76,77}$ It is believed that this effect is based on the stimulation of common precursors or the synergistic action with the endogenous macrophage CSF. In our study, the results of different G-CSF schedules on monocyte dynamics were roughly the same as for granulocyte dynamics. In other words, both filgrastim day 1 , $4 \times 10 \mu \mathrm{g}$ and pegfilgrastim day 1 were the best schedules with respect to monocytotoxicity in accordance to our findings for granulotoxicity.

We found no differences in lymphocyte toxicity between no G-CSF, the filgrastim schedules and the pegfilgrastim schedules. This might be not surprising, since G-CSF is considered to be lineage specific. On the other hand, there is some evidence that lymphopoiesis is also affected by G-CSF. ${ }^{78,79}$ There are also reports of a more favorable effect of pegfilgrastim on lymphopoiesis compared to filgrastim. ${ }^{80}$ However, we could not find these effects in our own data probably due to the smaller size of the effects. The only evidence found was a small but significant shift towards earlier occurrence of lymphocyte nadir for G-CSF schedules starting at day 0 . The latter effect as been found throughout all three lineages considered.

The results from our preclinical mouse model show that there is a high potential of optimizing G-CSF dosing and timing schedules for filgrastim but not for timing of pegfilgrastim. Despite of the wide use of pegfilgrastim as the more convenient G-CSF treatment, we believe that filgrastim will not vanish from clinical practice since corresponding schedules can be adapted and individualized more easily according to the clinical situation.

However, optimization of G-CSF prophylaxis also depends on the chemotherapeutic regimens used. Again, it is not possible to perform analogous experiments for all kinds of chemotherapeutic drugs. Hence, we aim to develop a biomathematical model of murine hematopoiesis under chemotherapy in analogy to our established model for humans. In order to construct a model which permits reliable quantitative predictions of hematotoxicity, precise data regarding the time courses of concomitantly measured blood cells and cytokine are required. Additionally, the analysis of bone marrow dynamics after the application of cytokines and/or chemotherapeutic drugs would also be needed. ${ }^{59}$

The planned models will allow quantitative predictions about the time course of bone marrow cell stages, circulating blood cells and cytokine concentrations for chemotherapeutic regimens not yet tested. Systematic model simulations of variable therapy parameters can lead to predictions about eg optimal application schedules of hematopoietic growth factors. Because of a larger database especially with respect to bone marrow cell dynamics in mice, we plan to construct these models in mice and humans in parallel by assuming the same physiological mechanisms but different model parameters.

Hence, our study is a part of a series of ongoing experiments aiming to provide the data necessary for our systems biologic approach.

\section{Disclosure}

MA, MK, and MS designed the study. MA and MK performed the experiments. MS performed the statistical analyses and wrote the paper. ML and FE contributed to the paper writing. All authors read and approved the final version of the manuscript. All authors report no conflicts of interest in this work.

\section{Acknowledgments}

We would like to thank Ms. Silke Lehnert very much for technical assistance. This research has been funded by a junior research grant of the Medical Faculty of the University of Leipzig (formel-1 project).

\section{References}

1. Epelbaum R, Faraggi D, Ben-Arie Y, et al. Survival of diffuse large cell lymphoma. A multivariate analysis including dose intensity variables. Cancer. 1990;66:1124-1129.

2. Gregory SA, Trumper L. Chemotherapy dose intensity in non-Hodgkin's lymphoma: is dose intensity an emerging paradigm for better outcomes? Ann Oncol. 2005;16:1413-1424. 
3. Hortobagyi GN. Progress in systemic chemotherapy of primary breast cancer: an overview. J Natl Cancer Inst Monogr. 2001:72-79.

4. Kwak LW, Halpern J, Olshen RA, Horning SJ. Prognostic significance of actual dose intensity in diffuse large-cell lymphoma: results of a tree-structured survival analysis. J Clin Oncol. 1990;8:963-977.

5. Marangolo M, Bengala C, Conte PF, et al. Dose and outcome: the hurdle of neutropenia. Oncol Rep. 2006;16:233-248.

6. Lepage E, Gisselbrecht C, Haioun C, et al. Prognostic significance of received relative dose intensity in non-Hodgkin's lymphoma patients: application to LNH-87 protocol. The GELA. (Groupe d'Etude des Lymphomes de l'Adulte). Ann Oncol. 1993;4:651-656.

7. Budman DR, Berry DA, Cirrincione CT, et al. Dose and dose intensity as determinants of outcome in the adjuvant treatment of breast cancer. The Cancer and Leukemia Group B. J Natl Cancer Inst. 1998;90:1205-1211.

8. von Minckwitz G, Raab G, Caputo A, et al. Doxorubicin with cyclophosphamide followed by docetaxel every 21 days compared with doxorubicin and docetaxel every 14 days as preoperative treatment in operable breast cancer: the GEPARDUO study of the German Breast Group. J Clin Oncol. 2005;23:2676-2685.

9. Blayney DW, LeBlanc ML, Grogan T, et al. Dose-intense chemotherapy every 2 weeks with dose-intense cyclophosphamide, doxorubicin, vincristine, and prednisone may improve survival in intermediate- and high-grade lymphoma: a phase II study of the Southwest Oncology Group (SWOG 9349). J Clin Oncol. 2003;21:2466-2473.

10. Pfreundschuh M, Trumper L, Kloess M, et al. Two-weekly or 3-weekly CHOP chemotherapy with or without etoposide for the treatment of young patients with good-prognosis (normal LDH) aggressive lymphomas: results of the NHL-B1 trial of the DSHNHL. Blood. 2004;104:626-633.

11. Shipp MA, Neuberg D, Janicek M, Canellos GP, Shulman LN. Highdose CHOP as initial therapy for patients with poor-prognosis aggressive non-Hodgkin's lymphoma: a dose-finding pilot study. J Clin Oncol. 1995;13:2916-2923.

12. Diehl V, Franklin J, Pfreundschuh M, et al. Standard and increased-dose BEACOPP chemotherapy compared with COPP-ABVD for advanced Hodgkin's disease. $N$ Engl J Med. 2003;348:2386-2395.

13. Sternberg CN, de Mulder PH, Schornagel JH, et al. Randomized phase III trial of high-dose-intensity methotrexate, vinblastine, doxorubicin, and cisplatin (MVAC) chemotherapy and recombinant human granulocyte colony-stimulating factor versus classic MVAC in advanced urothelial tract tumors: European Organization for Research and Treatment of Cancer Protocol no. 30924. J Clin Oncol. 2001;19:2638-2646.

14. Thatcher N, Girling DJ, Hopwood P, Sambrook RJ, Qian W, Stephens RJ. Improving survival without reducing quality of life in small-cell lung cancer patients by increasing the dose-intensity of chemotherapy with granulocyte colony-stimulating factor support: results of a British Medical Research Council Multicenter Randomized Trial. Medical Research Council Lung Cancer Working Party. J Clin Oncol. 2000;18:395-404.

15. Blayney DW, McGuire BW, Cruickshank SE, Johnson DH. Increasing chemotherapy dose density and intensity: phase I trials in non-small cell lung cancer and non-Hodgkin's lymphoma. Oncologist. 2005;10:138-149.

16. Wunderlich A, Kloess M, Reiser M, et al. Practicability and acute haematological toxicity of 2- and 3-weekly CHOP and CHOEP chemotherapy for aggressive non-Hodgkin's lymphoma: results from the NHL-B trial of the German High-Grade Non-Hodgkin's Lymphoma Study Group (DSHNHL). Ann Oncol. 2003;14:881-893.

17. Schwenkglenks M, Jackisch C, Constenla M, et al. Neutropenic event risk and impaired chemotherapy delivery in six European audits of breast cancer treatment. Support Care Cancer. 2006;14:901-909.

18. Siena S, Secondino S, Giannetta L, Carminati O, Pedrazzoli P. Optimising management of neutropenia and anaemia in cancer chemotherapy-advances in cytokine therapy. Crit Rev Oncol Hematol. 2003;48:S39-S47.

19. Kuderer NM, Dale DC, Crawford J, Cosler LE, Lyman GH. Mortality, morbidity, and cost associated with febrile neutropenia in adult cancer patients. Cancer. 2006;106:2258-2266.
20. Dale D. Current management of chemotherapy-induced neutropenia: the role of colony-stimulating factors. Semin Oncol. 2003;30:3-9.

21. Jacobson MA, Liu RC, Davies D, Cohen PT. Human immunodeficiency virus disease-related neutropenia and the risk of hospitalization for bacterial infection. Arch Intern Med. 1997;157:1825-1831.

22. Rodriguez-Adrian LJ, Grazziutti ML, Rex JH, Anaissie EJ. The potential role of cytokine therapy for fungal infections in patients with cancer: is recovery from neutropenia all that is needed? Clin Infect Dis. 1998;26:1270-1278.

23. Mitchell PL, Morland B, Stevens MC, et al. Granulocyte colonystimulating factor in established febrile neutropenia: a randomized study of pediatric patients. J Clin Oncol. 1997;15:1163-1170.

24. Garcia-Carbonero R, Mayordomo JI, Tornamira MV, et al. Granulocyte colony-stimulating factor in the treatment of high-risk febrile neutropenia: a multicenter randomized trial. J Natl Cancer Inst. 2001;93:31-38.

25. Pettengell R, Gurney H, Radford JA, et al. Granulocyte colonystimulating factor to prevent dose-limiting neutropenia in non-Hodgkin's lymphoma: a randomized controlled trial. Blood. 1992;80:1430-1436.

26. Crawford J, Dale DC, Lyman GH. Chemotherapy-induced neutropenia: risks, consequences, and new directions for its management. Cancer. 2004;100:228-237.

27. Begley CG, Nicola NA, Metcalf D. Proliferation of normal human promyelocytes and myelocytes after a single pulse stimulation by purified GM-CSF or G-CSF. Blood. 1988;71:640-645.

28. Lord BI, Bronchud MH, Owens S, et al. The kinetics of human granulopoiesis following treatment with granulocyte colony-stimulating factor in vivo. Proc Natl Acad Sci U S A. 1989;86:9499-9503.

29. Souza LM, Boone TC, Gabrilove J, et al. Recombinant human granulocyte colony-stimulating factor: effects on normal and leukemic myeloid cells. Science. 1986;232:61-65.

30. Colotta F, Re F, Polentarutti N, Sozzani S, Mantovani A. Modulation of granulocyte survival and programmed cell death by cytokines and bacterial products. Blood. 1992;80:2012-2020.

31. Mackey MC, Aprikyan AA, Dale DC. The rate of apoptosis in post mitotic neutrophil precursors of normal and neutropenic humans. Cell Prolif. 2003;36:27-34.

32. Bronchud $\mathrm{MH}$, Potter MR, Morgenstern $\mathrm{G}$, et al. In vitro and in vivo analysis of the effects of recombinant human granulocyte colonystimulating factor in patients. Br J Cancer. 1988;58:64-69.

33. Tanaka $\mathrm{H}$, Tokiwa $\mathrm{T}$. Influence of renal and hepatic failure on the pharmacokinetics of recombinant human granulocyte colony-stimulating factor (KRN8601) in the rat. Cancer Res. 1990;50:6615-6619.

34. Borleffs JC, Bosschaert M, Vrehen HM, et al. Effect of escalating doses of recombinant human granulocyte colony-stimulating factor (filgrastim) on circulating neutrophils in healthy subjects. Clin Ther. 1998;20:722-736.

35. Ericson SG, Gao H, Gericke GH, Lewis LD. The role of polymorphonuclear neutrophils (PMNs) in clearance of granulocyte colony-stimulating factor (G-CSF) in vivo and in vitro. Exp Hematol. 1997;25:1313-1325.

36. Khwaja A, Carver J, Jones HM, Paterson D, Linch DC. Expression and dynamic modulation of the human granulocyte colony-stimulating factor receptor in immature and differentiated myeloid cells. $\mathrm{Br} J$ Haematol. 1993;85:254-259.

37. Kotto-Kome AC, Fox SE, Lu W, Yang BB, Christensen RD, Calhoun DA. Evidence that the granulocyte colony-stimulating factor (G-CSF) receptor plays a role in the pharmacokinetics of G-CSF and PegG-CSF using a G-CSF-R KO model. Pharmacol Res. 2004;50:55-58.

38. El Ouriaghli F, Fujiwara H, Melenhorst JJ, Sconocchia G, Hensel N, Barrett AJ. Neutrophil elastase enzymatically antagonizes the in vitro action of G-CSF: implications for the regulation of granulopoiesis. Blood. 2003;101:1752-1758.

39. Shimazaki C, Uchiyama H, Fujita N, et al. Serum levels of endogenous and exogenous granulocyte colony-stimulating factor after autologous blood stem cell transplantation. Exp Hematol. 1995;23:1497-1502.

40. Crawford J. Clinical uses of pegylated pharmaceuticals in oncology. Cancer Treat Rev. 2002;28(Suppl A):7-11. 
41. Tanaka H, Satake-Ishikawa R, Ishikawa M, Matsuki S, Asano K. Pharmacokinetics of recombinant human granulocyte colonystimulating factor conjugated to polyethylene glycol in rats. Cancer Res. 1991;51:3710-3714.

42. Yang BB, Lum PK, Hayashi MM, Roskos LK. Polyethylene glycol modification of filgrastim results in decreased renal clearance of the protein in rats. J Pharm Sci. 2004;93:1367-1373.

43. Gabrilove JL. An analysis of current neutropenia therapies, including pegfilgrastim. Clin Cornerstone. 2006;8(Suppl 5):S19-S28.

44. Lord BI, Woolford LB, Molineux G. Kinetics of neutrophil production in normal and neutropenic animals during the response to filgrastim (r-metHu G-CSF) or filgrastim SD/01 (PEG-r-metHu G-CSF). Clin Cancer Res. 2001;7:2085-2090.

45. Grigg A, Solal-Celigny P, Hoskin P, et al. Open-label, randomized study of pegfilgrastim vs. daily filgrastim as an adjunct to chemotherapy in elderly patients with non-Hodgkin's lymphoma. Leuk Lymphoma. 2003;44:1503-1508

46. Holmes FA, Jones SE, O'Shaughnessy J, et al. Comparable efficacy and safety profiles of once-per-cycle pegfilgrastim and daily injection filgrastim in chemotherapy-induced neutropenia: a multicenter dose-finding study in women with breast cancer. Ann Oncol. 2002;13:903-909.

47. Schippinger W, Holub R, Dandachi N, Bauernhofer T, Samonigg H. Frequency of febrile neutropenia in breast cancer patients receiving epirubicin and docetaxel/paclitaxel with colony-stimulating growth factors: a comparison of filgrastim or lenograstim with pegfilgrastim. Oncology. 2006;70:290-293.

48. Pinto L, Liu Z, Doan Q, Bernal M, Dubois R, Lyman G. Comparison of pegfilgrastim with filgrastim on febrile neutropenia, grade IV neutropenia and bone pain: a meta-analysis of randomized controlled trials. Curr Med Res Opin. 2007;23:2283-2295.

49. Engel C, Scholz M, Loeffler M. A computational model of human granulopoiesis to simulate the hematotoxic effects of multicycle polychemotherapy. Blood. 2004;104:2323-2331.

50. Scholz M, Engel C, Loeffler M. Modelling Human Granulopoiesis under Poly-chemotherapy with G-CSF Support. J Math Biol. 2005;50:397-439.

51. Lohrmann HP, Schreml W. Cytotoxic drugs and the granulopoietic system. New York: Springer-Verlag; 1982

52. Barrios L, Poletti OH, Agustini MI. The influence of recombinant human granulocyte colony-stimulating factor on granulopoiesis in mice recovering from cyclophosphamide treatment. Methods Find Exp Clin Pharmacol. 2000;22:275-280.

53. Barrios L, Poletti OH. Effects of filgrastim on granulopoietic cells of mice pretreated with methotrexate. Biocell. 2005;29:7-14.

54. Coleman D, Fairchild D, Schindler-Horvat J, Munyakazi L, Neumann TA. Systemic effects of pegylated recombinant human megakaryocyte growth and development factor in combination with recombinant murine granulocyte colony-stimulating factor in a murine model of myelosuppression. Toxicol Sci. 1998;45:77-87.

55. Molineux G, Kinstler O, Briddell B, et al. A new form of Filgrastim with sustained duration in vivo and enhanced ability to mobilize PBPC in both mice and humans. Exp Hematol. 1999;27:1724-1734.

56. Pospisil M, Hofer M, Netikova J, et al. Pretreatment with granulocyte colony-stimulating factor reduces myelopoiesis in irradiated mice. Radiat Res. 1999;151:363-367.

57. Bauhofer A, Celik I, Plaul U, Wulf H, Torossian A. Effects of G-CSF and antibiotic prophylaxis in a $2 \times 2$ factorial design on outcome in septic rats. Inflamm Res. 2004;53(Suppl 2):S126-129.

58. Misaki M, Ueyama Y, Tsukamoto G, Matsumura T. Timing of recombinant human granulocyte colony-stimulating factor administration on neutropenia induced by cyclophosphamide in normal mice. Br J Cancer. 1998;77:884-889.

59. Yankelevich M, Goodell MA, Kaplan J. Efficacy of delayed administration of post-chemotherapy granulocyte colony-stimulating factor: evidence from murine studies of bone marrow cell kinetics. Exp Hematol. 2008;36:9-16.
60. Grigg AP, Roberts AW, Raunow H, et al. Optimizing dose and scheduling of filgrastim (granulocyte colony-stimulating factor) for mobilization and collection of peripheral blood progenitor cells in normal volunteers. Blood. 1995;86:4437-4445.

61. Bodey GP, Buckley M, Sathe YS, Freireich EJ. Quantitative relationships between circulating leukocytes and infection in patients with acute leukemia. Ann Intern Med. 1966;64:328-340.

62. Ihaka R, Gentleman RR. a language for data analysis and graphics. J Comp Graph Stat. 1996;5:299-314.

63. Petursson SR, Chervenick PA. Megakaryocytopoiesis and granulopoiesis following cyclophosphamide. J Lab Clin Med. 1982;100:682-694.

64. Yeager AM, Levin FC, Levin J. Effects of cyclophosphamide on murine bone marrow and splenic megakaryocyte-CFC, granulocytemacrophage-CFC, and peripheral blood cell levels. J Cell Physiol. 1982;112:222-228.

65. Chatta GS, Price TH, Allen RC, Dale DC. Effects of in vivo recombinant methionyl human granulocyte colony-stimulating factor on the neutrophil response and peripheral blood colony-forming cells in healthy young and elderly adult volunteers. Blood. 1994;84:2923-2929.

66. Johnston E, Crawford J, Blackwell S, et al. Randomized, dose-escalation study of $\mathrm{SD} / 01$ compared with daily filgrastim in patients receiving chemotherapy. J Clin Oncol. 2000;18:2522-2528.

67. Ribeiro D, Veldwijk MR, Benner A, et al. Differences in functional activity and antigen expression of granulocytes primed in vivo with filgrastim, lenograstim, or pegfilgrastim. Transfusion. 2007;47:969-980.

68. Tanaka H, Okada Y, Kawagishi M, Tokiwa T. Pharmacokinetics and pharmacodynamics of recombinant human granulocyte-colony stimulating factor after intravenous and subcutaneous administration in the rat. J Pharmacol Exp Ther. 1989;251:1199-1203.

69. Mukae H, Zamfir D, English D, Hogg JC, van Eeden SF. Polymorphonuclear leukocytes released from the bone marrow by granulocyte colony-stimulating factor: intravascular behavior. Hematol $J$. 2000;1:159-171.

70. Scholz M, Engel C, Loeffler M. Model-based design of chemotherapeutic regimens that account for heterogeneity in leucopoenia. $\mathrm{Br} \mathrm{J}$ Haematol. 2006;132:723-735.

71. Hematopoietic growth factors: ESMO Recommendations for the application. Ann Oncol. 2007;18(Suppl 2):ii89-ii91.

72. Weiss AJ, Lackman RD. Infusional chemotherapy combined with recombinant human granulocyte colony stimulating factor: advantages and limitations. Am J Clin Oncol. 1997;20:63-68.

73. Lokich J. Same-day pegfilgrastim and chemotherapy. Cancer Invest. 2005;23:573-576

74. Lokich JJ. Same day Pegfilgrastim and CHOP chemotherapy for nonHodgkin lymphoma. Am J Clin Oncol. 2006;29:361-363.

75. van Der Auwera P, Platzer E, Xu ZX, et al. Pharmacodynamics and pharmacokinetics of single doses of subcutaneous pegylated human G-CSF mutant (Ro 25-8315) in healthy volunteers: comparison with single and multiple daily doses of filgrastim. Am J Hematol. 2001;66:245-251.

76. Gilmore GL, DePasquale DK, Fischer BC, Shadduck RK. Enhancement of monocytopoiesis by granulocyte colony-stimulating factor: evidence for secondary cytokine effects in vivo. Exp Hematol. 1995;23:1319-1323.

77. Zhan Y, Lieschke GJ, Grail D, Dunn AR, Cheers C. Essential roles for granulocyte-macrophage colony-stimulating factor (GM-CSF) and G-CSF in the sustained hematopoietic response of Listeria monocytogenesinfected mice. Blood. 1998;91:863-869.

78. Nishihara M, Wada Y, Ogami K, et al. A combination of stem cell factor and granulocyte colony-stimulating factor enhances the growth of human progenitor B cells supported by murine stromal cell line MS-5. Eur J Immunol. 1998;28:855-864.

79. Yamada T, Kaneko H, Iizuka K, Matsubayashi Y, Kokai Y, Fujimoto J. Elevation of lymphocyte and hematopoietic stem cell numbers in mice transgenic for human granulocyte CSF. Lab Invest. 1996;74:384-394.

80. Vanstraelen G, Frere P, Ngirabacu MC, Willems E, Fillet G, Beguin Y. Pegfilgrastim compared with filgrastim after autologous hematopoietic peripheral blood stem cell transplantation. Exp Hematol. 2006;34:382-388. 
